\title{
International Tourism and Sustainable Development Challenges in Southern and Eastern Africa
}

\author{
Anna A. Suchkova* \\ Institute of Asian and African Studies, Lomonosov Moscow State University, 125009, Mohovaya 11, \\ Moscow, Russia
}

\begin{abstract}
The article discusses the role of international tourism and tourist companies in Eastern and Southern Africa in addressing sustainable development challenges such as hunger eradication, transition to affordable clean energy, climate change and ecosystem conservation. Facts and figures show that African companies that are developing their businesses within the framework of sustainable tourism can make a major contribution through their daily procedures to the challenges of biodiversity conservation, combating poaching and reforestation. The article investigates positive trends in business practices of African companies that operate in a globally competitive environment, such as the switch to solar energy in their tourist destinations. The main lines of action to mitigate the negative environmental and social consequences of the decline in international tourism due to the Covid-19 pandemic are highlighted.
\end{abstract}

\section{Introduction}

In the XXI century the rapid growth of tourism in a number of Eastern and Southern African countries has resulted in tourism industries playing a significant role in their economies, contributing considerably to their GDP and employment. In Namibia, Rwanda and Tanzania, tourism accounted for 15.5\%, $11.4 \%$ and $10.7 \%$ of their respective GDP in 2019 compared to $10.4 \%$, which represented the share of tourism in the global GDP. In Ethiopia, Zambia, Kenya and Botswana, this rate was slightly lower but still showed a noteworthy score of $6.8 \%$ to $9.6 \%$ [1]. All of the countries mentioned above, as well as South Africa, Uganda and Zimbabwe, have adopted national tourism development strategies where tourism is identified as a driving force of economic growth.

One of the main competitive advantages of African countries in the global tourism market is their exceptional biodiversity and the opportunity to travel in comfort across the wilderness. A variety of activities are offered to foreign and local tourists in national parks and private reserves where tourist camps and lodges are built. Tourism infrastructure development projects have generated mixed reactions from environmentalists and conservationists, who see them as a potential threat to the ecosystems of national parks. Local communities living near parks and reserves that are actively promoting tourism can also

\footnotetext{
*Corresponding author: onemoresuchkova@gmail.com
} 
express discontent with the losses they might incur due to the changes in their traditional business environment. Thus, the balance of costs and benefits for individual territories is not always positive. To counterbalance the negative effects that accompany the expansion of tourism-related businesses and to reconcile the people's interests with nature conservation, sustainable tourism concepts were developed.

The Covid-19 pandemic caused the biggest crisis in tourism history. From January to May 2021, the number of tourists visiting Africa decreased by 81\% compared to 2019 [2]. However, this suspension has provided an opportunity to reassess the role of tourism not only from an economic point of view but also as a tool for implementing sustainable development plans.

This article discusses the role of tourist companies in Eastern and Southern Africa in addressing hunger, improving the health and well-being of local communities, energy conservation and use of clean energy, and ecosystem conservation in general.

\section{Sources and Methods}

For the purpose of writing this article, data from the reports of international organizations were analyzed and systematized, such as World Tourism Organization, World Tourism and Travel Council, World Wildlife Fund, Food and Agriculture Organization of the United Nations (FAO), African Union, and others. Publications by tourism professionals, investigations into the illegal trade in wildlife, websites of travel companies in Tanzania, Kenya and Botswana, surveys of travel companies' employees in Tanzania, South Africa and Zimbabwe were also used while working on this article.

\section{Results and Discussion}

\subsection{Climate change, hunger and the role of international tourism}

Climate change, population growth and armed conflict have resulted in 250 million people in Africa (19.1\% of the population) suffering from undernourishment. Africa is the secondlargest region in the world in absolute terms and the largest in proportion of the starving population. Malnutrition is particularly acute in Eastern Africa, which has the highest absolute number of undernourished population in sub-Saharan Africa: according to FAO in 2019 , it accounted for half of the total undernourished population in the subcontinent, i.e. 117.9 million out of 234.7 million people. The situation in Southern Africa is much better, but according to the FAO forecasts, the number of starving people in the region will double by 2030 [3].

The complexity of hunger and malnutrition challenges requires a range of coordinated interventions ranging from international and government programs to targeted projects at the village level aimed at adapting to climate change, improving agricultural productivity and reducing postharvest losses. To meet these challengers, tourist companies in Eastern and Southern Africa work in two different ways. First, they work with local communities to implement agricultural quality standards that would enable farmers to become food suppliers for the tourist companies, improve the marketability of their farms and increase income. To illustrate how difficult this could be, we will consider the case of Greystoke Mahale - a lodge located on the shore of Lake Tanganyika (Tanzania). In local villages, agriculture is cultivated on small farms, and its products are used for personal consumption. Poor seed quality, rudimentary production technologies, lack of harvest storage facilities, poor roads or complete lack of them - all of the above made it virtually impossible for a five-star lodge to buy food locally. It took considerable effort and time on the part of lodge managers to turn 
subsistence farming into a supplier of vegetables. In 2019, according to Greystoke Mahale managers, they began working with local poultry farmers. They also set up a fund to raise money to build a road to one of the villages. Without downgrading the merits of numerous projects by international and governmental organizations aimed at educating farmers to improve agricultural productivity and marketing, we would like to emphasize the important advantage of the tourist companies' strategy, which guarantees a market for farmers and provides clear incentives for them to adopt new technics.

The Covid-19 pandemic, which reduced the number of tourists traveling to Africa by more than a half, has undermined the ability of farmers to sell agricultural products and handicrafts to tourist camps, reduced their cash income and aggravated the problem of hunger. The proportion of the undernourished population has increased in all countries, including the relatively prosperous Southern African region. In Botswana and Namibia, this rate was $17 \%$ and $22 \%$, respectively, in September 2021. In tourism countries in East Africa, these figures are somewhat lower, but the absolute number of starving people is estimated at millions: in Kenya -8 million people, in Tanzania - 5 million [4]. In this context, direct assistance to people suffering from hunger and malnutrition becomes more and more prominent. This is the second major effort undertaken by responsible tourist companies in their fight against hunger. In Tanzania, Nomad company provides 1,500 schoolchildren in three primary schools with hot meals every school day [5]. Most parents in villages around Ruaha National Park, where the Ruaha Carnivore project is being implemented, cannot afford to pay for their children's lunches at school. As a result, children often did not attend school or dropped out early. Therefore, such projects not only help to combat malnutrition, but also support another important goal of sustainable development: affordable education.

\subsection{Forest loss and rehabilitation}

The existing economic models in African countries, especially in rural areas, result in a conflict between the challenges of preserving the environment and eradicating hunger. Low agricultural productivity and high losses (up to a third) of food during storage and transportation provide a strong incentive to expand arable land, including at the expense of forests. Involvement in illegal timber extraction and its further sale is becoming a source of survival for many low-income families. The loss of forest area is also due to legal commercial logging, burning of wood for charcoal and its subsequent use for cooking and heating. The challenges of survival conceal the fact that forest loss in the short term will lead to serious deterioration of their lifestyle - drying out of rivers, lack of drinking water, droughts and bad harvest are the direct results of the destruction of forests. Eco-activists are working with local communities in a number of countries to raise awareness of the need for forest conservation and rehabilitation. However, these efforts will be of little use unless they are supported by measures to increase agricultural productivity, improve access to alternative energy sources, restrain illegal logging, and manage forest rehabilitation.

In the territories granted on concession to safari operators, the protection of forests and bushes from illegal logging becomes the direct responsibility of the concessionaire, and its financing is partly covered by the revenues from tourist activities. For example, the Phinda Forest Lodge, located in the private Phinda Resource Reserve in Kwazulu Natal Province of South Africa, organizes mass weeding to remove invasive plants to preserve the unique forest. In Kenya, Serena company, which owns a network of hotels and camps throughout the country, developed its own reforestation program. The program includes planting in company-owned land endemic drought-resistant tree species, such as Acacia, Mellia, Croton and Commiphora. Every hotel guest gets the opportunity to plant «his» or "her" tree. Recognizing the importance of forests in combating desertification and mitigating negative impacts of climate change, the company has also been planting forests in local communities' 
land, involving in such activities neighboring schools and accompanying these events with educational presentations [6]. The efforts of tourist companies to maintain forests and support their rehabilitation are also important for the conservation of various animal species, which is essential for the development of tourism in African countries.

\subsection{Green energy initiatives by tourist companies}

The problem of energy shortage in Africa is so acute that even the pandemic has not removed it from the agenda. This is well attested for by the publication of the joint report of the African Development Bank (ADB) and the African Union Development Agency "New Partnership for African Development", dedicated to the African energy masterplan, which appeared on the websites of these organizations on 23 October 2020. According to ADB, "over 640 million Africans have no access to energy, corresponding to an electricity access rate for African countries at just over 40 percent, the lowest in the world. Per capita consumption of energy in sub-Saharan Africa (excluding South Africa) is $180 \mathrm{kWh}$, compared to $13,000 \mathrm{kWh}$ per capita in the United States and 6,500 kWh in Europe» [7].

The challenges of climate change and the fight against carbon emissions provide an incentive to address energy deficiency by shifting to clean energy. However, most African families, especially those living in rural areas, cannot afford to buy solar panels or biogas devices. Therefore, all known projects on the continent are carried out at the expense of international organizations such as ADB, the European Union, WWF, etc. The scale of the task does not imply quick solutions, but there are some encouraging examples to date. In Tanzania, 350 households in two pilot villages received access to solar energy. Biogas devices replaced $30 \%$ of wood and coal stoves. Similar programs are being implemented in Madagascar and Uganda. The Government of Madagascar has decided on a national program for the training of solar engineers. It is planned that 750 women will be trained under this program, who will then service 630,000 households that will be provided with solar energy facilities [8].

For tourist companies that have facilities in national parks and reserves, electricity supply is a serious problem. The majority of tourist camps use diesel generators. And the severity of the problem lies not only in the high cost of fuel and its transportation to remote locations, but also in the accusations coming from the environmentalists who object to the use of diesel generators in nature reserves and parks. Tourist companies are under even greater pressure from potential clients, who want not only to enjoy every moment of being exposed to a unique natural environment, but through their participation as tourists hope to maintain and preserve this uniqueness. Thus, renewable energy and eco-efficiency are turning into marketing strategies that companies in Southern and Eastern Africa use to sell their tourism products.

There are several eco-efficiency strategies that are currently being used in tourism businesses in Eastern and Southern Africa. The first is to replace diesel generators with solar panels. According to the Ecotourism Society of Kenya, of the 87 camps and hotels ranked as the most environmentally friendly, 10 camps have switched to solar power. At Tortilis camp a power plant consisting of 110 solar panels and equipped with inverters and batteries is controlled by a digital system that even calculates the amount of Carbon (IV) Oxide emissions avoided. A further 45 camps and lodges from the ranking list use solar energy in combination with other types of sources such as diesel fuel, liquefied gas, charcoal briquettes, and firewood [9]. A similar shift from diesel to solar energy is observed in Botswana. For example, out of 22 camps owned by Okavango Wilderness Safaris and located in the Okavango delta, 10 are completely solar-powered. Switching from diesel to solar energy had a positive economic impact on the company. The company's report states that the complete conversion of five camps to solar energy has resulted in cost savings of almost $\$ 400,000$. However, more than $80 \%$ of tourist destinations in the country still use fossil fuels [10]. The 
same situation is in Ethiopia, which in 2018 became the world leader in tourism growth. Surveys show just isolated cases of using solar energy for power supply of camps and lodges in the country [11].

The second strategy for improving the environmental performance of the tourism business is to apply various energy-saving practices, including use of energy balances, energy-saving lamps, elimination of sockets in guest tents and houses, etc. Jack's Camp, which is located in the Kalahari Desert and recreates the atmosphere of a XIXth century camp, abandoned electricity altogether, replaced it with oil lamps, and provided access to it only in public areas. The third eco-efficiency strategy is to manage the resources used, including control over the quality of diesel fuel and the disposal of spent fuel.

The importance of the environmental responsibility issues in marketing strategies of African tourist companies competing for global markets is evidenced by the fact that on their English-language sites, these companies inform their potential clients about the company's energy efficiency and energy conservation achievements. For example, a Kenyan company Serena has announced that it has equipped its Kilaguni Serena Safari Lodge in Tsavo National Park with a power plant consisting of 960 solar panels, covering $95 \%$ of the camp's electricity needs [6]. Asilia company, which manages tourist facilities in four East African countries (Tanzania, Kenya, Rwanda and Uganda), in its 2019/2020 report informed interested readers that during that period it was able to offset $\mathrm{CO} 2$ emissions by 1,425 tons, which is equivalent to the removal of some 118 medium-sized vehicles from traffic for a year [12].

\subsection{Biodiversity conservation, tackling poaching and illegal wildlife trade}

The development of tourism in Africa is directly linked to the wildlife conservation. The decline in animal populace is due not only to climate change, population growth, economic pressure on the environment, but also to poaching and illegal trade in African animals. Existing estimates of losses in the tourism industry due to poaching can only give an approximate picture. According to these estimates, elephant poaching costs the continent $\$ 25$ million per year. The impact of poaching is particularly evident in Eastern and Southern Africa, where national and private parks provide the bulk of tourism revenue. According to David Sheldrick Wildlife Trust, in 2014 Africa's tourism industry, local communities, and economies together have lost more than $\$ 44.5$ million to poaching alone. A survey of 216 protected areas in 2016 showed that there is a consistent inverse correlation between the number of tourists and their expenditures on the one hand and the elephant population on the other. Decline in the rhino population has the same negative effect on tourism. According to Ecologic Institute, in 2006-2014 rhino poaching resulted in a total annual loss to tourism revenue in the South African Republic, Namibia, Kenya and Zimbabwe of between $€ 205.76$ million and $€ 230.76$ million. Moreover, according to the Institute's estimates the extinction of one species from the "Big Five" (elephant, rhino, buffalo, lion, leopard) reduces ecotourism by $20 \%$ [13].

There are three kinds of poaching. First is killing animals for food. It is carried out by residents of villages located near protected areas. The second category of poaching is illegal commercial hunting. Finally, the third and most dangerous group of poachers are poachers who are members of international criminal alliances that organize the killing, transportation and sale of rare animals (such as pangolins) and animal parts (rhino horn and ivory). The third category of poachers is the most dangerous one - consequences of their activities are not limited to economic losses only.

Poachers kill not only animals, but rangers who guard them. The number of people killed in clashes with poachers vary but they are all in the hundreds [14]. Paramilitary guards sent to protect animals from poaching raise tensions in local communities, which see the military as a threat to their normal way of life. On the other hand, the residents of protected areas are 
under constant pressure from criminal groups to join in their criminal activities. These groups are extremely difficult to oppose. They are very well equipped: they have not only weapons, but also night vision devices, helicopters and small aircraft at their disposal. Such resources are not available to the police and environmental agencies involved in tackling poaching. Investigations carried out by the authorities of African countries and international organizations show that organized crime comprises representatives of different countries, and that there is a «division of labor» among them. Hunters are either local residents or foreign recruits. For example, employees of national parks and private reserves in South Africa reported that most poachers were Mozambique nationals. Criminal managers bribe police, customs and national parks officers. A recent trial held a few years ago in South Africa, revealed that leaders of one of the criminal groups were white people - lawyers, attorneys and even veterinarians [15].

Until recently, the main markets for ivory and rhino horns were in China, Vietnam and Arab countries. At the end of 2017 China imposed a ban on trade in ivory and ivory products. Factories producing these products were closed. Legal markets have moved to neighboring countries. And while a black market continues to operate in China, the impact of measures undertaken by the Chinese authorities remains to be significant. A consumer survey conducted in China in April 2021 showed that demand for ivory declined by $43 \%$ after the ban on trade was introduced [16]. As a result, the price of elephant tusks in Southern and Eastern Africa has fallen dramatically and have ceased to compensate for the high risks associated with organized poaching of elephants.

Attempts to solve the problem of illegal trade in rhino horns by means of bans have so far failed. In China and Vietnam it is still used in traditional medicine as a cure for a range of diseases, including cancer. Although numerous studies have shown no positive effect of rhino horn powder, surveys of Chinese consumers show that almost half of them buy rhino horn for medical purposes. Another $12 \%$ buy it as a luxury item and as protection against inflation (the price of a kilo of horn in 2012-13 was $\$ 60,000$ ) and more than $20 \%$ pursue both objectives [17]. However, a quarter of the respondents were unaware of the ban on the horn trade, and most of them did not consider the information on the catastrophic decline in the number of rhinos to be important for their purchasing preferences. The failure to protect rhinos by altering demand, which worked in the case of ivory, has intensified the search for other means to tackle rhino poaching. Measures being considered include legalization of trade in cut-off horns of rhinos, grown on farms or in private reserves, and production of synthetic horns.

For tourist companies, the fight against all types of poaching is an important part of their daily activities and a significant addition to their expenses. Patrolling the territories, removing snares and traps, building fences, cutting off rhino horns to prevent their killing, and educating the local population - to name just a few of its components. In souvenir shops located at tourist camps the product range is strictly monitored to ensure that no product made from an endangered plant or animal is sold there. Recently, there has been a tendency to label the products of these shops with tags containing information on environmentally friendly production methods and the target use of the proceeds of their sale. These targets generally include reforestation, protection of individual species and support to local communities. Such information is also part of the companies' marketing strategies to attract a special group of high-income tourists who appreciate conservation efforts and are willing to spend money for a noble cause.

The Covid-19 pandemic has aggravated the poaching problem. As a result of the pandemic, there was practically no tourists and visitors entering the national parks and private reserves, and that greatly facilitated poachers' access to the closed areas. The loss of income by local residents due to the closure of tourist camps has forced people to engage in illegal hunting which previously they did not dare to do. Disturbing information comes from all over 
the world. In Ethiopia at the beginning of the summer 2020 at least 6 elephants were killed in a single day, compared to 10 elephants killed in all 2019, which became the «largest slaughter» in the country ever to be recorder. It turned out difficult to apprehend the perpetrators because local residents living in the Mago National Park area were armed and unwilling to cooperate with the officials [18]. In the North of Serengeti National Park in Tanzania in 2020, the rangers rescued thousands of animals, removing 9,000 snares and saving 135 animals from traps [19].

\section{Conclusion}

Tourist companies in Eastern and Southern Africa, committed to sustainable and responsible tourism, can contribute to solving many critical environmental and social problems. Being engaged in the international tourism market competition, they are under pressure from consumers, competitors and the environmental community to move towards a more environmentally friendly tourism. The need to maintain their main competitive advantage unique biodiversity and beautiful landscapes - compels them to invest their resources, time and energy in conservation of endangered species. In search for solutions to prevent conflicts with local communities, which often and not without reason view tourism activity close to their habitat as undesirable due to the loss of resource base and change in their natural living conditions, tourist companies came up with numerous economic and social initiatives to compensate for these losses. First of all, these initiatives include commitments to hire and buy locally, to provide funds for scholarships, medical treatment and food to members of local communities, etc. Originally driven by business reasoning, these initiatives presently become the best practices and eventually develop into social responsibility standards of sustainable tourism companies. The associations of tourist companies that exist in all countries of the region contribute to the dissemination of these standards.

The Covid-19 pandemic, which has dramatically halted international tourism to Africa, led to the increase in the number of hungry and undernourished people, including those who directly or indirectly depended on tourism. Another unfortunate consequence of the decline in tourism was the increase in poaching in the deserted parks and reserves.

\section{References}

1. Economic Input Reports, Country, Region Data, https://wttc.org

2. International Travel Largely On Hold Despite Uptick In May, https://www.unwto.org

3. The State of Food Security and Nutrition in the World 2020, http://www.fao.org

4. World Food Programme. HungerMap, https://hungermap.wfp.org

5. Nomad Conservation Partners and Communities, https://www.gofundme.com

6. Serena News. Insights and Inspirations in the World of Serena Hotels, 8 (2018) https://www.ethosmarketing.co.uk

7. Africa's energy masterplan takes shape as African Development Bank and AUDANEPAD release key report, https://www.afdb.org

8. Conservation: The People's Perspective. WWF AfricaFY17, 15

9. Ecotourism Kenya, https://ecotourismkenya.org

10. J. E. Mbaiwa et al., Int. J. Tourism Policy, 8, 1 https://www.inderscienceonline.com 
11. Eco-Lodges and Tourist Infrastructure Development in and Around Abijata Shalla Lakes National Park; From the Perspective of Evaluating their Sustainability, Journal of Tourism, Hospitality and Sports, www.iiste.org

12. An International Peer-reviewed Journal, 45 (2019) https://www.researchgate.net

13. Positive Impact 2019/20, https://www.asiliaafrica.com

14. Tackling Illegal Wildlife Trade in Africa: Economic Incentives and Approaches, https://www.chathamhouse.org

15. The Price of Protecting Rhinos, https://www.theatlantic.com

16. Millions seized in rhino horn smuggling group, https://www.gov.za

17. Demand for Elephant Ivory in China Drops to Lowest Level Since National Ban, https://www.worldwildlife.org

18. An Undercover Investigation on Rhino Horn Trafficking in China and Vietnam, https://elephantleague.org

19. Six elephants killed in one day by poachers in Ethiopia, https://www.theguardian.com

20. Nomad Conservation Partners and Communities, https://www.gofundme.com 